\title{
Kidney Procurement System in Colombia: A System Dynamics Approach*
}

\section{Sistema de obtención de riñones en Colombia: un enfoque basado en la Dinámica de Sistemas}

\section{Sistema de obtenção de rins na Colômbia: uma abordagem baseada na Dinâmica de Sistemas}

Date received: 17 April 2017. Date accepted: 26 August 2017. Date published: 27 May 2019

DOI: https://doi.org/10.11144/Javeriana.rgps18-36.kpsc

\author{
Joan Paola Cruz \\ Escuela Colombiana de Ingeniería Julio Garavito, Colombia \\ ORCID: 0000-0002-5343-9055 \\ William J. Guerrero ${ }^{a}$ \\ Universidad de la Sabana, Colombia \\ ORCID: 0000-0002-9807-6593 \\ Edna Rocío Pérez \\ Escuela Colombiana de Ingeniería Julio Garavito, Colombia \\ ORCID: 0000-0002-0659-2794 \\ David L. Lizarazo \\ Escuela Colombiana de Ingeniería Julio Garavito, Colombia \\ ORCID: 0000-0002-4178-3617 \\ Paula C. Rico \\ Escuela Colombiana de Ingeniería Julio Garavito, Colombia \\ ORCID: 0000-0003-1260-1236 \\ Ana María Castillo \\ Escuela Colombiana de Ingeniería Julio Garavito, Colombia \\ ORCID: https://orcid.org/0000-0002-4166-8459 \\ Laura N. Torres \\ Escuela Colombiana de Ingeniería Julio Garavito, Colombia \\ ORCID: https://orcid.org/0000-0002-3734-8858
}

How to cite this article: Cruz JP, Guerrero WJ, Pérez ER, Lizarazo DL, Rico PC, Castillo AM, Torres LN. Kidney procurement system in Colombia: A System Dynamics approach. Revista Gerencia y Políticas de Salud. 2019;18(36). https://doi.org/10.11144/Javeriana.rgps18-36.kpsc

\footnotetext{
* Research article

a_Corresponding author. E-mail: william.guerrero1@unisabana.edu.co
} 


\section{Abstract}

Objective: This paper presents an analysis of two regulatory proposals in response to the growing demand for kidney transplants in Colombia. The results can be useful in evaluating these possible policy interventions once they have been implemented. Methods: The proposed model uses System Dynamics as a tool to understand the behavior of this complex social system if two intervention projects are executed. The first is a bill of law seeking to expand the legal presumption of organ donation. The second one is to implement a Kidney Exchange Program. The analysis is made in two parts. Firstly, a causal loop diagram is proposed. Secondly, the simulation of the system using a stock and flow diagram is analyzed. Results: Results show that the projects can balance the system and encourage donations. Conclusion: The implementation of a KEP is recommended since it achieves stability of the system earlier than the amendment to the law, with a reduction in the waiting list size.

Keywords: kidney exchange program, System Dynamics modeling, healthcare, kidney transplantation, organ procurement system

\section{Resumen}

Objetivo: Este artículo presenta un análisis de dos propuestas de regulación en respuesta a la creciente demanda de trasplantes de riñón en Colombia. Los resultados pueden ser útiles al evaluar esas posibles intervenciones en las políticas una vez han sido implementadas. Métodos: El modelo propuesto emplea la Dinámica de Sistemas como herramienta para entender el comportamiento de este complejo sistema social cuando se ejecutan dos proyectos de intervención. El primero es un proyecto de ley que buscan expandir la presunción legal de la donación del órgano. El segundo es la implementación de un Programa de intercambio de riñones (KEP). El análisis se realiza en dos partes: primero se propone un diagrama causal; en segundo lugar, se analiza la simulación del sistema usando un diagrama de existencias y flujos. Resultados: Los resultados muestran que los proyectos pueden equilibrar el sistema y motivar las donaciones. Conclusión: Se recomienda la implementación de un programa KEP dado que logra la estabilidad del sistema antes que la enmienda de las leyes, con una reducción en el tamaño de la lista de espera.

Palabras clave: programa de intercambio de riñón, modelos de Dinámica de Sistemas, atención médica, trasplante de riñón, sistema de obtención de órganos

\section{Resumo}

Objetivo: Este artigo apresenta análise de duas propostas regulatórias em resposta à crescente demanda por transplantes renais na Colômbia. Os resultados podem ser úteis na avaliação das possíveis intervenções nas políticas, uma vez implementadas. Métodos: O modelo proposto usa a Dinâmica de Sistemas como uma ferramenta para compreender o comportamento desse complexo sistema social quando executados dois projetos de intervenção. O primeiro é um projeto de lei visando expandir a presunção legal da doação de órgãos. O segundo é a implementação de um Programa de troca de rins (KEP). A análise é realizada em duas partes: primeiro propõe-se diagrama causal; segundo, analisa-se a simulação do sistema usando um diagrama de estoque e fluxo. Resultados: Os resultados mostram que os projetos podem equilibrar o sistema e motivar as doações. Conclusão: Recomenda-se a implementação de um programa KEP uma vez que alcança a estabilidade do sistema antes da alteração das leis, com uma redução no tamanho da lista de espera.

Palavras-chave: programa de troca de rins, modelos de Dinâmica de Sistemas, atendimento médico, transplante renal, sistema de aquisição de órgãos 


\section{Introduction}

Kidneys are vital organs of the human body whose functions include producing hormones, removing waste products from the blood, and regulating water fluid levels that allow a chemical balance in the body. Kidneys are healthy if they do not present a reduction of their renal function, which is the capacity of filtering blood. Factors such as age, genetics, high blood pressure, and diabetes can permanently reduce renal function. This is known as Chronic Kidney Disease (CKD). CKD is defined as the progressive loss of the rate of glomerular filtration that often results in uremia and death (1). Although its progression can be delayed, CKD does not have a known cure. This disease is categorized into five stages. In stages 1, 2 and 3, the objective of the medical treatment is to preserve renal function. In stage 4 , renal function is heavily reduced, and in stage 5, hemodialysis and kidney transplant are the only options to keep the patient alive.

During 2015 in Colombia, the number of patients in stages 4 and 5 that were registered in the kidney transplant waiting list was over 2000 , and the number of performed transplants was 768 (2). About $17.3 \%$ of these transplantations come from living donors. Donations from patients with asystole are not practice in Colombia. This shows the imbalance between kidney donors and the waiting list. On the other hand, CKD deaths rise to 26.9 per 100,000 inhabitants (3). This behavior needs understanding, considering its complexity.

A System Dynamics (SD) model representing this situation is a helpful tool to determine the factors and impacts that the changes in the system will cause in the future and allows studying the effect of the implementation of strategies to improve its behavior. The developed model considers the bill 1805 of 2016 that aims to amend article 2 of Law 73 of 1988 of the Republic of Colombia, which extends the legal presumption of organ donation to people did not state their will to forbid organ donations in life. Thus, every Colombian citizen who dies will be an organ donor unless they declare against it in life. Examples of SD models analyses to simulate disease trends and projections are presented by Huang et al. (4) who proposed an SD model to study the evolution of the Kawasaki disease in Taiwan and the US; and Shin et al. (5) who study the Middle East Respiratory Syndrome Coronavirus in the Republic of Korea. 
In addition, the model considers the implementation of a Kidney Exchange Program (KEP) in Colombia. This program consists on contacting CKD patients that have a voluntary living kidney donor (a relative, spouse or a friend) with no histocompatibility and they are willing to participate in finding a couple in the same situation (no donor-recipient histocompatibility) and swap donors. The KEP has been implemented in countries such as South Korea (6), Switzerland (7), The United States (8-10), Turkey (11), Romania (12), Netherlands (13-15), United Kingdom (16-18), Portugal, Canada, New Zealand, and Australia (19).

To the best of our knowledge, there are no records in Colombia of studies about kidney donation and procurement analysis using SD. Nonetheless, within the studied literature two approaches are using this tool in other countries.

The first refers to the kidney transplant system focused on reducing the waiting list and illegal kidney traffic. Fakkert, Schwarz y Pruyt (20) developed an SD model that simulates the behavior of the waiting list for kidney transplantation in the United States from 2012 to 2030. This model shows that by 2030, the waiting list for kidney transplantation will have doubled when compared to 2012 and the main analysis shows the change in the waiting list system if different laws or norms are applied. They conclude that the only strategy that showed a significant drop in the waiting list was the application of economic compensation in health treatments for living donors. However, this financial compensation is illegal in many countries, and this market is often considered repugnant (21).

Paricio and Fidal (22) analyze how the transplant system is impacted by adopting social policies such as the opportunity for an altruistic donor to affiliate three people needing a transplant, of their choice, into a prioritization system on the waiting list. They conclude that this strategy needs to be complemented by others to balance kidney demand and supply.

Although there are no records in Colombia of studies using SD, the increasing demand for kidney procurement problem has been studied by many authors from other areas of management science. One of them is a proposal to increase the number of transplants in Colombia from the perspective of operations research. Bruni, Conforti, Sicilia, and Trotta (23) propose an integer programming model to locate and allocate resources for the kidney transplantation system in Italy, aiming to minimize the inequality in waiting 
times of different regions in the country. Fajardo-Vallejo (24) developed a mathematical model using simulated samples of incompatible patient-donor pairs to determine if an exchange is possible, given the pool of pairs. In that case, they find the maximum number of such pairs that would be included in the KEP. They conclude that KEP can yield a significant increase in the number of organ transplantation in Colombia. Villa and Patrone (25) studied the mechanism design of the KEP from a game theory point of view, assuming three different information levels, based on the observation of the Italian case. They conclude that the players are motivated to manipulate their information to get better kidneys under any information assumption. Also, Ahmadvand and Pishvaee (26) present a study on the system of kidney allocation using a Data Envelopment Analysis (DEA) model inspired by the Iranian system. They propose to evaluate the efficiency of possible patient-organ pairs for kidney allocation and perform experiments using a series of data realizations for different credibility levels.

Ünver (27) studied the problem under the objective of minimizing average waiting cost using a stochastic optimization model. By assuming Poisson arrivals, the paper proves that certain dispatching rules for kidneys constitute an optimal policy. Zenios (28) models the KEP as a birth and death process, where no patients expire but the long wait is penalized by a cost. The objective is to maximize the average quality-adjusted life years and the optimal policy that limits the number of patients that can take part in pairwise exchange is analytically derived. Thompson et al. (29) proposed a simulation model to evaluate different policies for allocating kidneys and increase the efficiency of the system, considering only cadaveric donors in the US.

From this literature review, it is concluded that, although most of these previous studies have been carried out in the context of the United States, they provide a guideline for modeling the donation, procurement and transplantation system in the Colombian context.

The proposed model considers Colombian social dynamics, political constraints, health system capacity, and the Colombian population biological features. For this reason, the development of this model is relevant to improve key performance indicators of publicly and privately funded healthcare systems, based on the analysis of the current and future situation of the dynamics that affect waiting lists and kidney transplants. Thus, new strategies that generate the maximum benefit for the population may be proposed. 
For example, our model will allow in the future to simulate and analyze the impact of investing in strategies to treat the causes of CKD such as genetic factors, high blood pressure, and diabetes.

The following section explains the methodology developed together with the established models. Then, the results and findings are discussed in section 3. Finally, section 4 presents the discussion of the findings and limitations of the proposed methodology, conclusions and future research.

\section{Materials and Methods}

$\mathrm{SD}$ is a systemic tool that allows to understand a complex system from a qualitative and quantitative point of view and to simulate possible scenarios and intervention strategies to improve its behavior. The identification of the causal relationships between variables of a system is the first step, followed by the detection of the behaviors that generate balance in the system or reinforcement effects (30). A recent literature review on SD models applied to health systems modeling by Chang et al. (31), concluding that SD can capture the dynamic interactions between different components of a health system to predict the consequences of policy interventions, and provide critical insights on the evolution of the system.

The present study uses SD to conceptualize the kidney donation and procurement system in Colombia, identifying the main actors and their causal relationships. Then, behavioral scenarios simulations are performed to explore the impacts of two intervention projects aimed at decreasing the number of patients in a kidney transplantation waiting list.

The methodology steps are the following. First, a model of causal loops is constructed reflecting the behaviors of the system that are currently presented in Colombia. The proposed models are build based on interviews that were performed to experts and operators of the logistic systems in a Colombian private company dedicated to kidney transplantation procedures with experience of more than 2000 transplantation procedures performed to date. We made unstructured interviews to allow experts to expose their points of view and standard practices. Further, the literature presented in the article is a source of information for the model. Two intervention projects are included in the model to determine, in qualitative terms, what the behavior of the system would be and how its loops are affected as a result of the changes in its structure. 
The two projects are: first, the amendments to article 2 of law 73 of 1988 of the Republic of Colombia, stated in article 3 of law 1805 of 2016, which extend the legal presumption of organ donation to people who have died and did not state their will to forbid organ donations. This assumption means that every Colombian citizen who dies will be an organ donor if they did not declare against it in life. The second project is the implementation of a KEP in Colombia. It consists on contacting CKD patients that have a voluntary living kidney donor (a relative, spouse, or a friend) with no histocompatibility and that are willing to voluntarily participate in finding a couple in the same situation (no donor-recipient histocompatibility) and swap donors.

The second step, a model of stocks and flows corresponding to the model of causal loops previously elaborated is constructed, and using simulation, it expands the prior analyses and quantitatively evidences the impact over time that the projects can have in the system. Finally, using the developed models, results are discussed enhancing main findings regarding the kidney procurement system in Colombia. The following subsections detail the proposed models.

\section{Causal Loop Diagram}

The first approach to model the system is by proposing a causal loop diagram. Figure 1 presents the model that describes the current kidney transplant and donation system in Colombia. It is divided into three subsystems which interact through the variables that connect them. The first subsystem is denoted as CKD Diagnosis. It considers the patients within the healthcare system suffering from CKD or those who are susceptible to become ill. The subsystem models how patients are detected and treated for CKD while discriminating patients diagnosed at early stages of the disease (stages 1-3) from those patients with late diagnosis (stages 4-5). Also, there is a proportion of patients with an early diagnosis that start a treatment to avoid the evolution of the disease and a proportion of patients who deteriorate rapidly during the treatment.

Within this subsystem, the reinforcing loop, denoted as Early diagnosis of CKD, is identified. The loop begins with the detection of patients in stages 1, 2 or 3 . Subsequently, they are treated in order to prevent their progression into stages 4 and 5. Therefore, the number of these patients who reach the waiting list does not increase. Consequently, fewer CKD associated deaths are expected, since, at a global level, the Colombian population increases and therefore the population in the health system increases as well. Thus, when more people 
are sick, more early detection is expected. This behavior indicates the need to strengthen the methods for early detection of $\mathrm{CKD}$ and to invest in strategies to treat the causes of the disease such as diabetes and high blood pressure. It is concluded that this loop does not present a dominant behavior in the system. However, it is relevant since, if its dominance in the system increased, it would have an effect in favor of reducing people reaching stages 4 and 5, and this would reduce the number of patients in the waiting list.

Once patients are in advanced stages of the disease (4 and 5), they are registered in the waiting list for organ transplantation, if approved by an ethics committee. The dynamics of this subsystem is modeled in the subsystem denoted as Waiting List, which represents those patients with CKD willing to have transplant surgery. In the meantime, these patients are treated with hemodialysis procedures, which affect their quality of life as this procedure is performed about three times a week, it has an average duration of 4 hours per session, and it must be performed until they receive a transplanted kidney. Some patients on the waiting list will never be transplanted as a result of donor deficit in the country, as evidenced in the first half of 2015 where 17 patients died waiting for a kidney transplant ${ }^{2}$. This subsystem considers the proportion of patients with successful kidney transplantation is reducing CKD deaths and those who ultimately remain on the waiting list because they had a transplantation surgery but rejected the transplant after a negative immunological response.

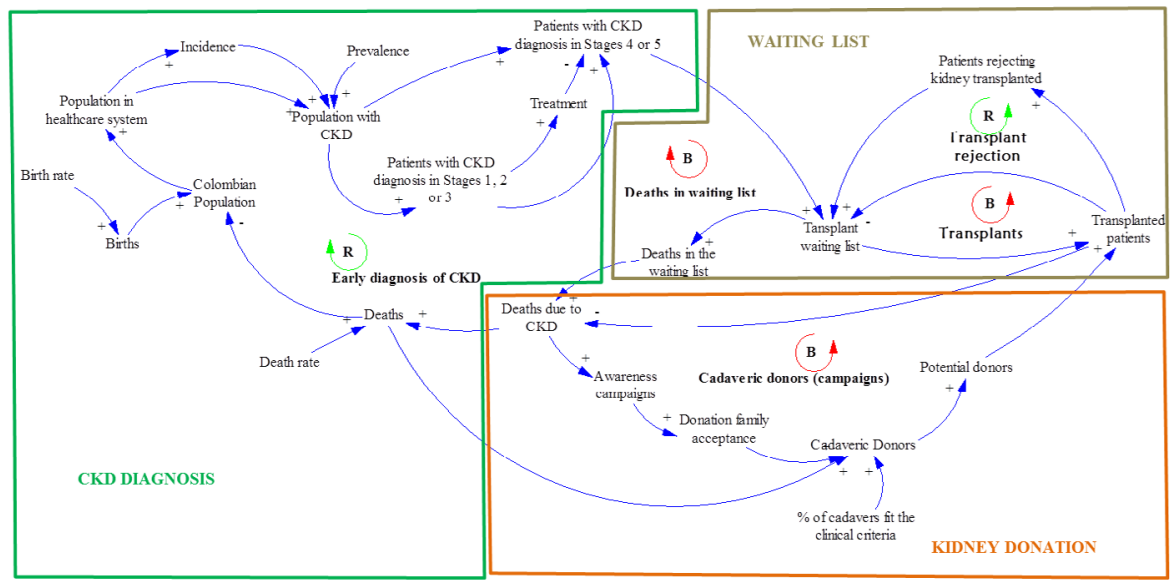

Figure 1. Causal Diagram: Kidney transplant and donation system in Colombia - Current scenario Source: own work 
For this subsystem, three feedback loops were identified. We have denoted them as Transplant, Deaths in the Waiting list, and Transplant Rejection. The first is the most relevant for the system, the more people on the list, then there would be more transplants, and with more transplants, fewer people on the list. It would be expected to have a dominant balancing behavior in the system since the transplants that are performed should cover the demand for kidneys and thus, the waiting list should decrease. However, demand for kidneys tends to grow faster than the transplanted patients (2). The second loop, denoted as Deaths in Waiting List, balances the system with the growing number of patients dying while waiting for a kidney transplant. When people are diagnosed on stages 4 and 5, the transplant waiting list is increased. It should be clarified that although this is a balancing loop, it is not desired for the system, because it is expected that the waiting list will decrease thanks to successful kidney transplants and not due to the death of patients while they wait. Similarly, the Transplant Rejection loop reinforces the increase of the waiting list with patients returning to it after being transplanted, but their transplantation procedure fails (32).

The third subsystem is denoted as Kidney Donation subsystem. It contemplates the people who become potential donors of organs and tissues after they die or before dying in the case of coma state or brain death with the consent of their relatives, and the cadaveric donors who stated their will to donate before dying and their kidneys are viable for donation (33). It does not consider donations from patients with asystole since it is not a practice in Colombia. Together, all these potential donors increase the number of transplants, decreasing the number of deaths in the system and generating a balanced behavior. As this loop dominates, the system behavior is improved in terms of reducing the transplant waiting list. Currently, this loop, although desired, does not dominate the system either. In real life, many other variables affect the number of cadaveric donors. These may include under-detection of donors, failures in the maintenance of hemodynamic stability, issues while diagnosing brain death, or administrative or legal barriers such as the unavailability of resources to retrieve the organs which often happen in Colombia (about 9.7\% of the cases) [34]. In our modeling approach, we will consider living donors as part of the KEP. Official statistics show an average of 132 transplantations coming from living donors per year with a steady behavior (34). 
Figure 2 represents the model of the system when implementing the first project. It evaluates the behavior of the system if an amendment is made to Law 73 of 1988 of the Republic of Colombia, eliminating any possibility for a patient's relative to deny their organ donation. The model is modified so that the acceptance percentage of the family does not have an incidence in the number of cadaveric donors. The total number of potential donors increases in this scenario, leading to a higher number of transplants performed and resulting in a reduction in the waiting list.

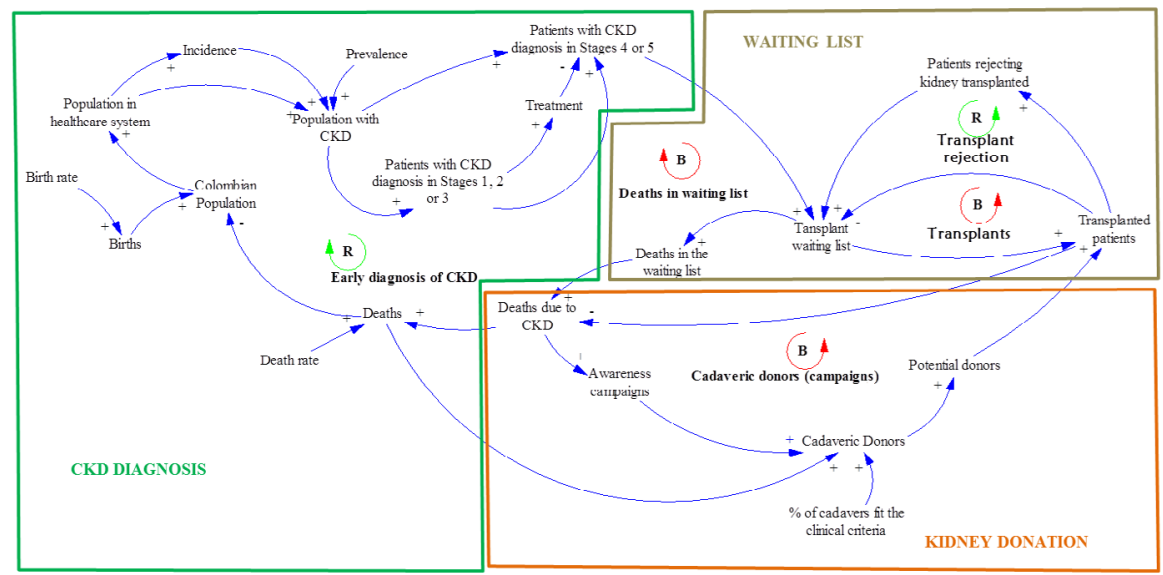

Figure 2. Causal Diagram: Kidney transplant and donation system in Colombia - Project 1 : Amendment to Law 73 of 1988

Source: own work

The loop denoted as cadaveric donors (campaigns) is a balancing loop intensified by the awareness of the disease among the population. Through effective governmental awareness campaigns, a higher number of donors can be found. These campaigns are motivated when the number of CKD deaths is perceived to be significant. Furthermore, cadaveric donors represent the major source of kidneys for the system. It is estimated that the number of transplants from cadaveric donors is 10.4 per million inhabitants and the number of transplants from living donors is 1.9 per million inhabitants (28). However, this balancing loop is not currently dominating in the Colombian system because about $37 \%$ of the relatives of the potential cadaveric donor decline donation. Thus, an increase of 2.2 percentage points compared to 2014 has been observed. An increasing donation is ideal for the system because it balances the offer of kidneys with the transplants required in the 
waiting list. Nevertheless, it is not growing at the same pace as the waiting list is. This demonstrates the need to implement strategies such as this first project that seeks to amend Law 73 of 1988 to achieve an increase in the number of cadaveric donors.

Figure 3 shows the model of the system when implementing the second project. It evaluates the behavior of the system if a KEP is implemented in Colombia as it has been used in other countries. In the model, it is possible to qualitatively demonstrate that the number of donors increases in the proposed scenario since each patient wanting to enter the program, is required to report a relative or a friend willing to donate one of his kidneys. That way, every patient might get a kidney while helping to increase the pool of donors simultaneously. This program is useful for patients that have a relative or friend willing to donate but that it is not compatible with their immune system so that they can find other couples in the same situation and swap donors. This reinforcing loop improves the behavior of the kidney donation subsystem by increasing the number of transplanted patients, resulting in decreasing the number of deaths of CKD patients, which neutralizes the number of CKD deaths in the waiting list. This encourages more couples (patient-donor) to participate in the program, increasing the pool of donors again. In sum, as the KEP becomes successful, the loop will dominate in the system improving its behavior by reducing the waiting list.

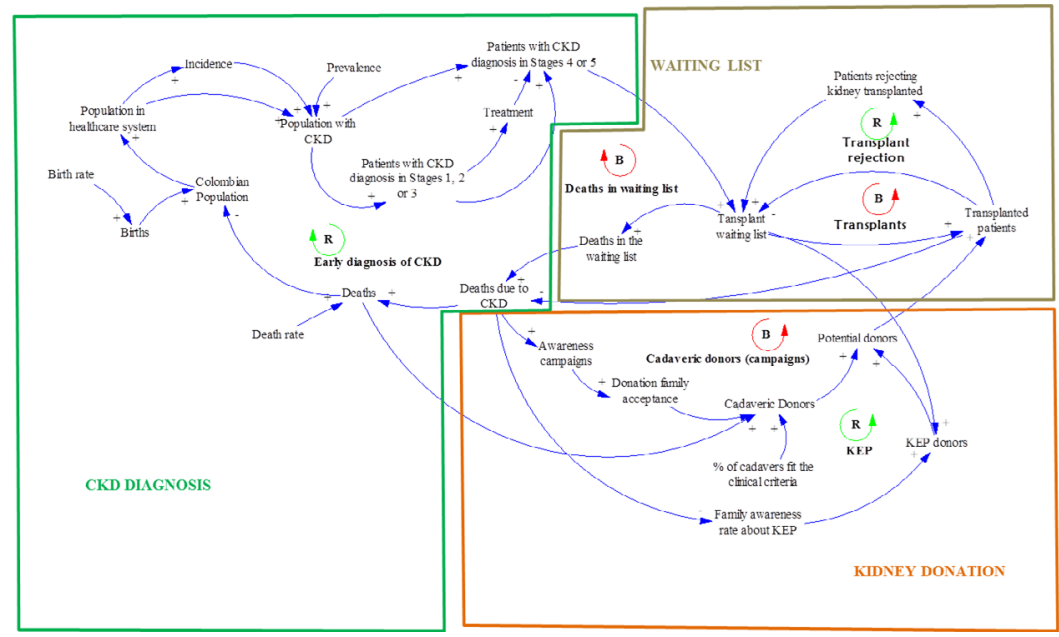

Figure 3. Causal Diagram: Kidney transplant and donation system in Colombia - Project 2: KEP Source: own work 
In this instance, it is possible to consider the hypothesis that the government decided to increase the investment in disease awareness campaigns. As a result, the early detection of the disease (stages 1, 2 or 3 ) where treatment is possible, is expected to increase. In other words, investing in awareness campaigns will result in the early detection of the disease and, in turn, provide adequate prevention, reducing the likelihood of getting CKD and further delay the patients evolving to stage 4 or 5 as shown in the following loop diagram (Figure 4). These campaigns must include not only the means for detecting patients on early stages but the mechanisms to guarantee that every patient detected will receive and commit to a medical treatment program.

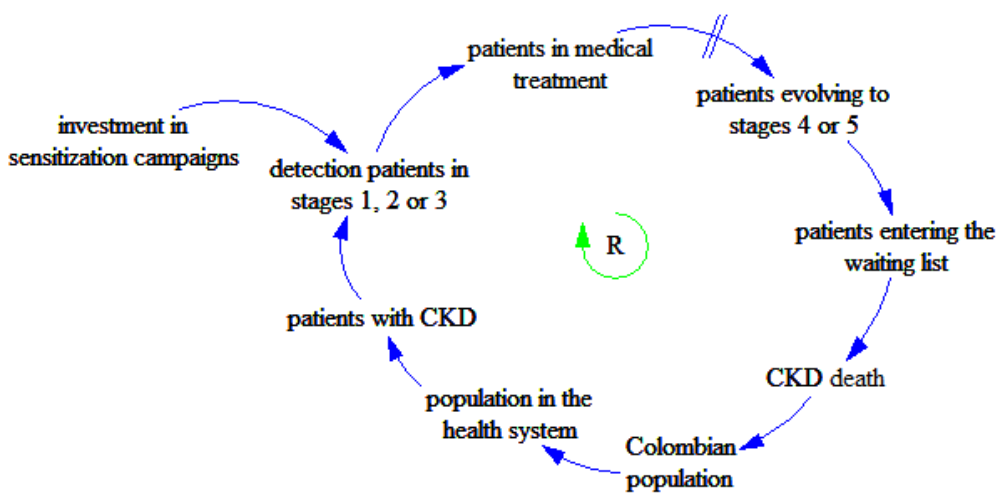

Figure 4. Causal Loop of Investment in Awareness Campaigns

Source: own work

\section{Stock and Flow Diagram}

The first qualitative approach to model the kidney transplantation system in Colombia is complemented by a quantitative approach proposing a stock and flow model also known as a Forrester diagram. The current situation modeled using this second approach is presented in Figure 5. We made the following assumptions to formulate this model. First, the time it takes for patients in stage 1, 2 or 3 to reach more advanced stages of the disease (stages 4 or 5) is calculated as a weighted average represented as a delay. Second, factors such as birth and death rates, the proportion of patients admitted to the waiting list, and the number of patients who suffer from transplant rejection are considered to remain constant throughout the simulation. Official data sources were consulted such as the National Ministry of Health to set the values of variables. Appendix A presents the list of the fixed variables and their respective data sources. The associated parameters are 
estimated using the historical ratio of incidence and prevalence data. The incidence ratio is defined as the frequency of appearance of new cases of a disorder in a period, while prevalence ratio is the proportion of individuals in a population who have the disease at any time (35).

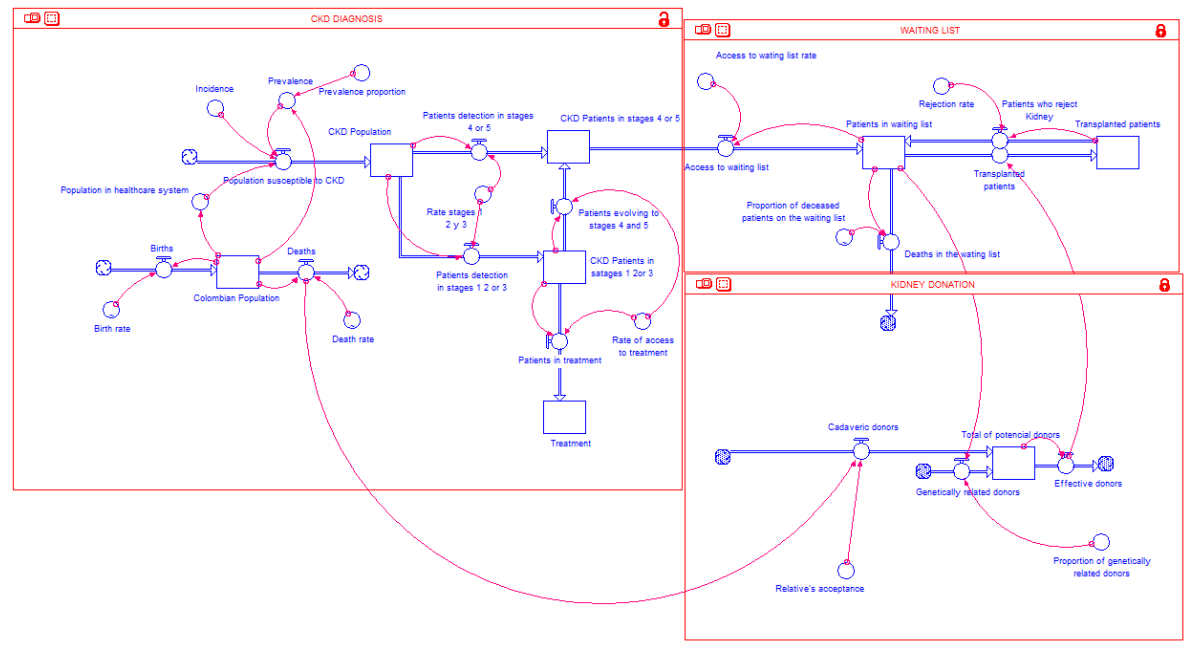

Figure 5. Stocks and Flows Model: Kidney transplant and donation system in Colombia - Current scenario

Source: own work

To implement the first project, the model is modified in order to simulate the effect of the application of the amendment to Law 73 of 1988 of the Republic of Colombia, which eliminates the possibility for potential cadaveric donor relatives to decline organ donation of the patient (see Figure 6).

The modified model also incorporates the fact that there is a clinical criterion to select donors. Not all people are eligible as candidate kidney donors because of medical factors, even if there is the will to donate. The number of donors in the system will increase but not in the same proportion of deaths. 


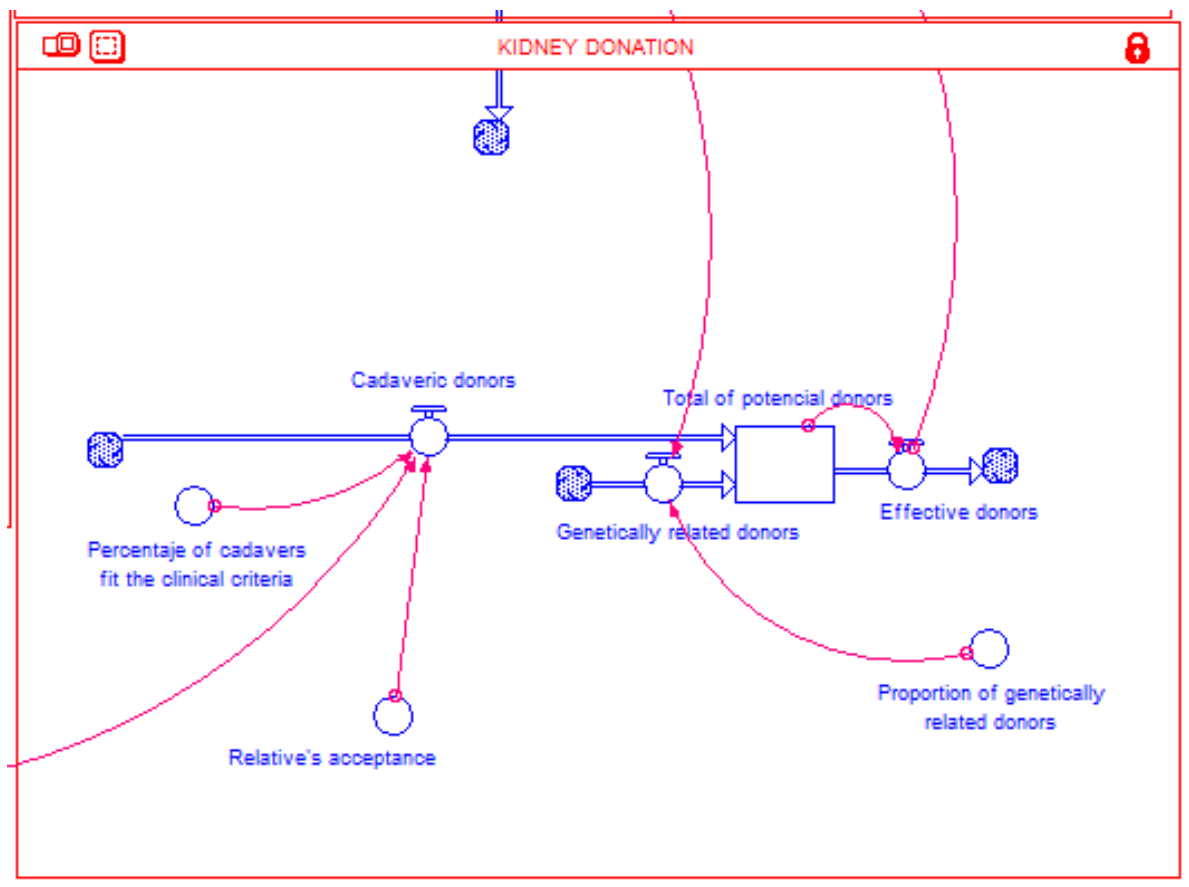

Figure 6. Stocks and Flows Model: Kidney donation Subsystem - Amendment to Law 73 of 1988

Source: own work

To implement the second project, the original stocks and flows model is modified to simulate the situation where the KEP is implemented in Colombia (See Figure 7). 


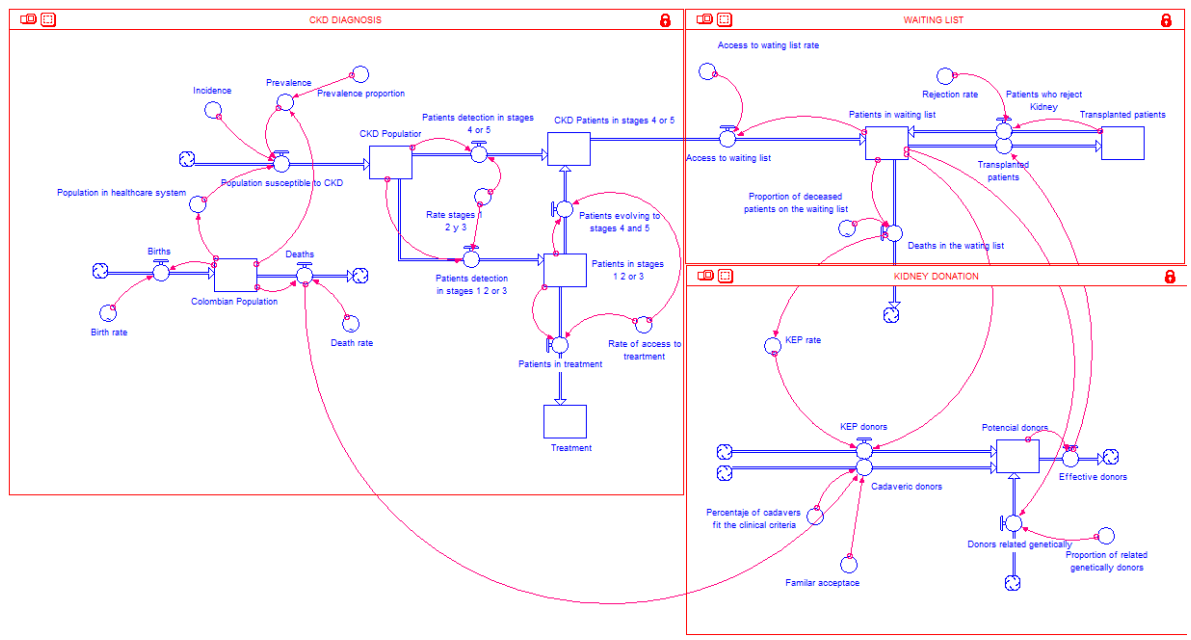

Figure 7. Stocks and Flows Model: Kidney transplant and donation system in Colombia - Project 2: KEP

Source: own work

Given that the impact of the implementation of the KEP in Colombia is unknown, three different scenarios are made based on the same assumption: if fewer people die on the waiting list, the more reliable the KEP program will be. Therefore, the dynamics of the rate of KEP donors is assumed as the inverse to the number of deaths on the waiting list. These scenarios have the following variables: the number of deaths of patients registered in the waiting list is the independent variable. The Colombian Health Ministry keeps historical data on the mortality of people requesting a kidney transplant. On the other hand, the donor rate is a dependent variable since a KEP has never been implemented in Colombia, then the impact of the implementation of KEP is unknown.

The three scenarios are evaluated as follows (see Appendix B): the first scenario simulates the behavior where a favorable and constant KEP donor acceptance rate is described, but when the number of deaths on the waiting list increases, the rate of KEP donors will gradually decrease. The second scenario assumes that the acceptance rate is associated with an interval of the number of deaths of patients registered in the waiting list. The third scenario shows an accelerated decline, assuming there is less confidence in the program because of the number of deaths of patients registered in the waiting list. The behavior of the system does not vary significantly with different scenarios. For the sake of brevity, only the first one is presented in figure 8. It is selected because it shows the most favorable results on the waiting list dynamics. 


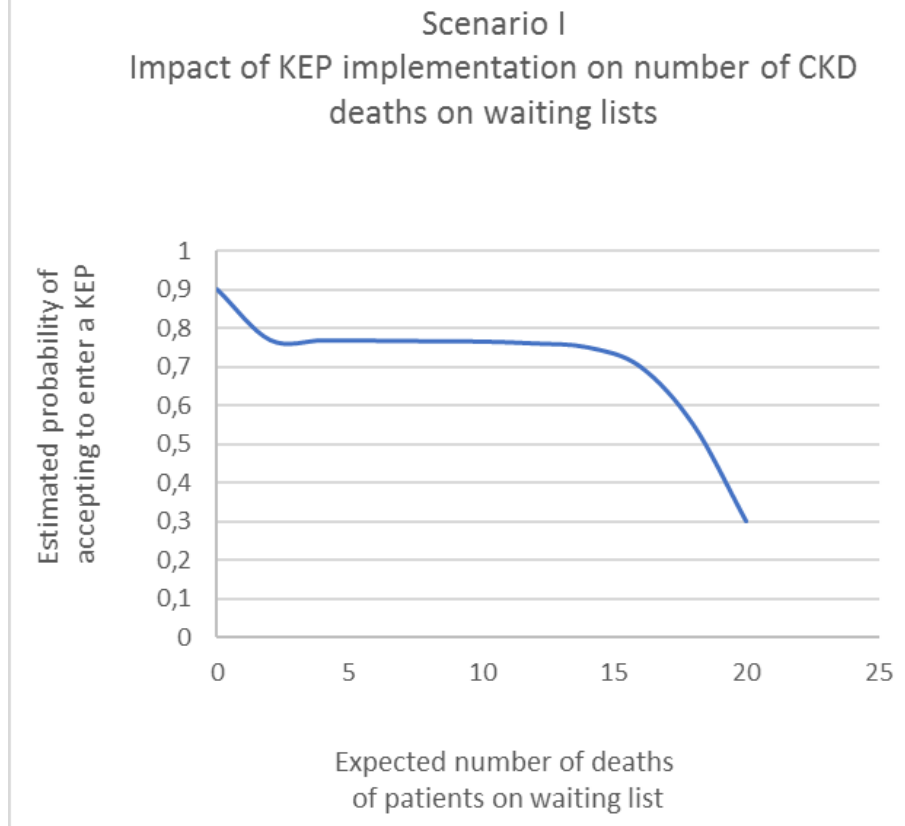

Figure 8. First Scenario, Impact of KEP implementation on number of CKD deaths on waiting list Source: own work

In figure 8 , the acceptance decreases from a value of 0.9 to 0.3 as the number of CKD deaths increase from 0 to 20 based on the historical data of the number of deaths of patients registered in waiting lists in recent years. It is important to clarify that this relationship is an assumption and therefore it is possible that there are variations in the behavior of the KEP donor rate if implemented in Colombia. Next section discusses the results obtained after simulating the stocks and flows models developed.

\section{Results}

The presented analysis is based on a simulation performed within a time horizon of 29 years (2016-2045). The results in this section analyze the behavior of the system through a stocks and flows model (Forrester Diagram) from a quantitative point of view and complement those found using the qualitative approach exposed in section 2 with the causal loops diagrams. Four scenarios are discussed: the first one is the current situation in Colombia 
where neither the legal reform nor the KEP have been implemented. The second one involves the amendment to Law 73 of 1988 of the Republic of Colombia (3). The third one includes the implementation of the KEP in the system. Finally, the fourth one is the combination of the second and third scenarios. The last three scenarios are compared with the first one using two performance indicators. These contribute to clarify the panorama of the kidney demand found in each one of the scenarios. Besides, they allow to analyze the behavior of the proposed projects in terms of their effectiveness in reducing the waiting list.

Indicator 1 measures the proportion to which potential donors cover the need for transplanting in the waiting list, which allows knowing how the system is balanced to equal the required transplant demand. Indicator 2 shows the proportion of the Colombian population that enters the waiting list and its evolution over the years. Finally, the proportion of potential donors belonging to the KEP is useful for monitoring the implementation of this program and its acceptance in the Colombian population.

\section{First Scenario: Current Situation}

Figures 9 and 10 indicate the results of the simulation under the current system situation. It is noted that during the first 19 years of the simulation of the kidney donation and transplantation system in Colombia, the proportion of Colombians entering the waiting list (Indicator 2) and transplanted patients has a stable, increasing behavior (see Figure 9), while the proportion of waiting list patients who are transplanted (Indicator 1) decreases at an accelerated pace (see Figure 10). This can be explained because the waiting list grows in proportion with the Colombian population while potential donors, which in this case are mostly composed by cadaveric donors, follows a pattern of the mortality rate and fails to grow at the same rate. This is true under the assumption of maintaining the mortality rate at 5,870 deaths per thousand populations, and the percentage of family acceptance of the donation at $63 \%$ (3). 


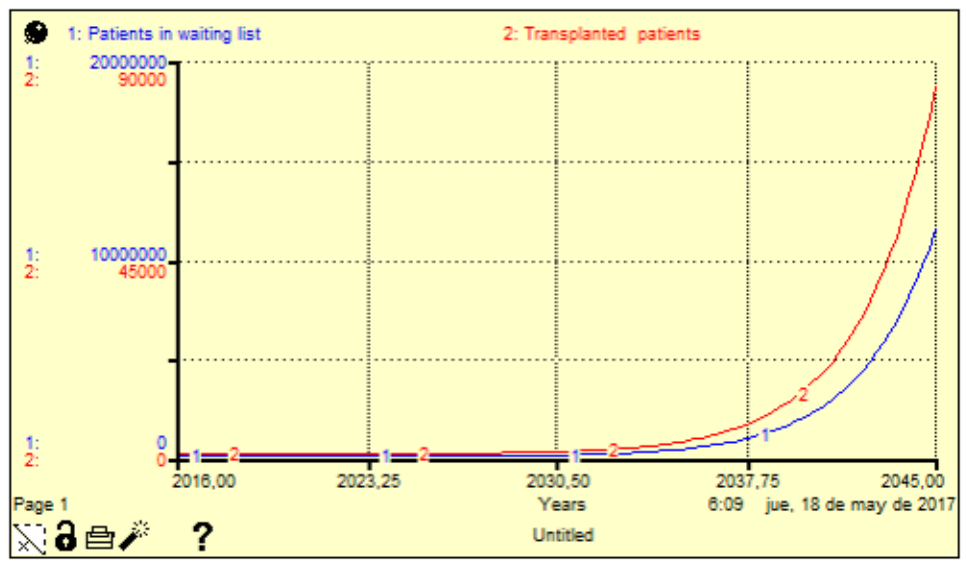

Figure 9. Simulation of the waiting list size and number of transplanted patients under current system conditions

Source: own work

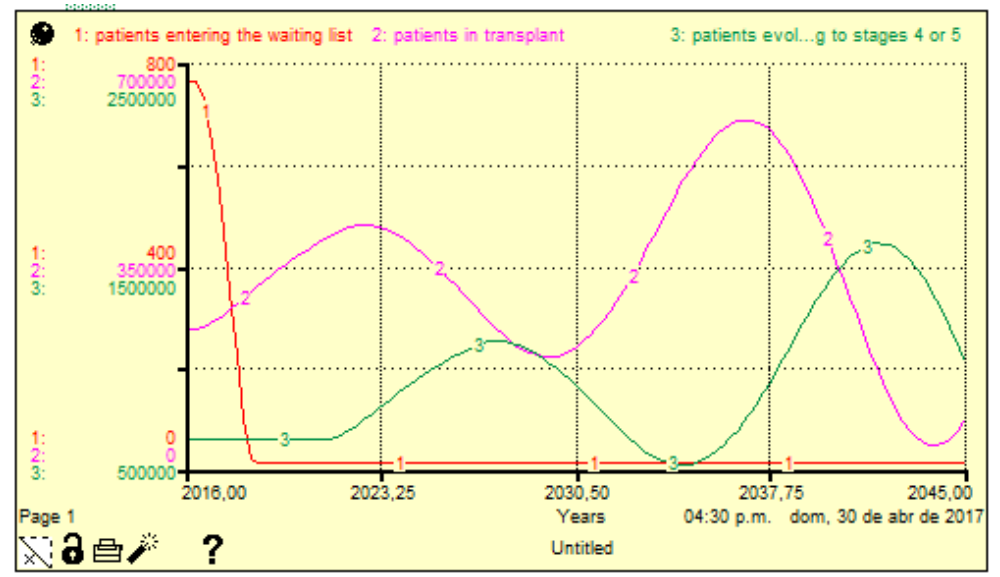

Figure 10. Simulation of performance indicators, under current system conditions

Source: own work

Sensitivity analysis was performed in this situation regarding the rate of acceptance versus the rate of death. In a first instance we proposed the hypothesis that if the acceptance rate remained at $63 \%$, but the death rate per thousand inhabitants grew by $340 \%$, the list would reduce and stabilize quickly because enough donors would be available to meet the demand. In another instance where the death rate is more likely to remain constant and the acceptance to increase to $80 \%$, it was found that although the waiting 
list could be reduced, it would not be enough to stabilize the donation and kidney transplantation system in Colombia.

However, after the 20th year, the proportion of citizens entering the waiting list has an exponential growth due to an increasing number of people who become ill with $\mathrm{CKD}$ at stages 4 or 5 . On the other hand, the number of patients at stage 1, 2 or 3, and stage 4 or 5 of the disease presents an oscillatory and growing behavior. Figure 11 shows that although patients are detected in early stages, eventually the number of patients in advanced stages predominates because not all receive medical treatment to slow the disease evolution to the point where kidney transplantation is required. Thus, under the current conditions, the system will continue to present a deficit in the donation of kidneys, and therefore the waiting list will continue to grow over time, reinforced by the fact that few patients are treated in early stages of the disease (stages 1 - 3).

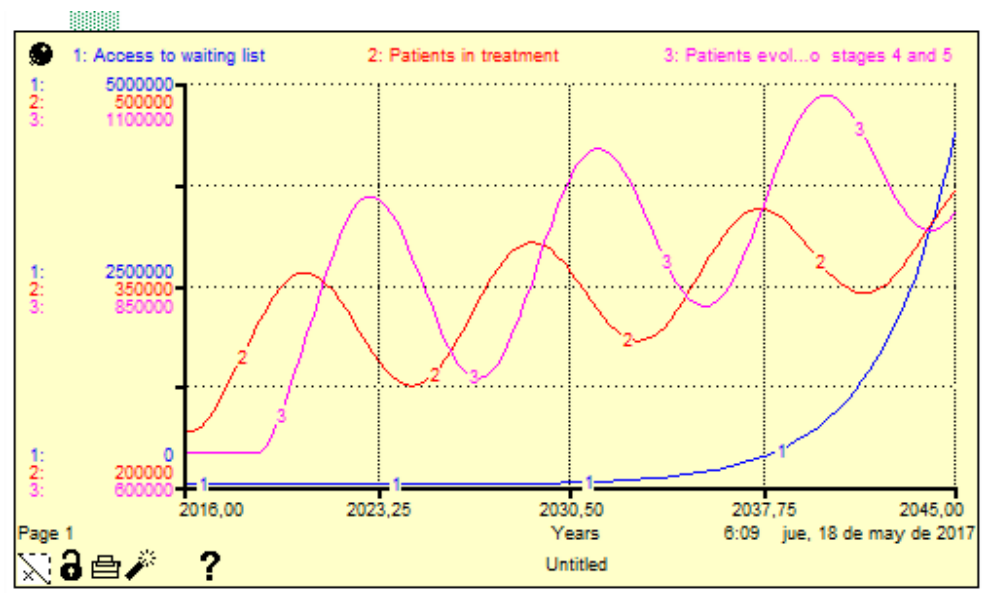

Figure 11. Simulation of number of patients entering the waiting list, number of patients in transplant and patients evolving to stages 4 or 5 , under the current system conditions

Source: own work

\section{Second Scenario: Legal Reform}

The analysis of the project to amend to Law 73 of 1988 is addressed in this section. Indicator 1 presents a significant growth in the year 2022, showing that the proportion of donors covering the waiting list increases dramatically up to about $98 \%$ in the period from 2016 to 2022 . This is due to the decrease in the waiting list size obtained for that time interval. This 
decrease also impacts indicator 2 , which is reduced over the same time period indicating that the reform has a positive impact on the waiting list. Furthermore, achieving stability for the next years in this interval. In addition, when comparing the current number of cadaveric donors against the results obtained with the approval of reform for the last year of simulation, a $60 \%$ improvement is noticed. Then, this is a favorable scenario to cover the demand for kidneys in the country, and therefore it is desirable to accept the amendment to Law 73 of 1988 that forces about $100 \%$ acceptance of organ donation for cadaveric donors.

\section{Third Scenario: KEP}

If Colombia decides to adopt a KEP, the system would achieve a favorable behavior through time, because it reduces the waiting list until reaching a point of balance. This represents a significant improvement over the current situation since the program allows the number of transplanted patients to exceed the annual entry of people to the waiting list

Regarding the KEP donor rate, there is evidence of an increase during the first years of the simulation because there is an intrinsic relationship between the deaths on the waiting list and the KEP donors. Namely, as the number of deaths decreases there will be more patients and relatives willing to cooperate and therefore a higher chance of finding a KEP donor

It is important to emphasize that the simulation was carried out contemplating the assumption that once the KEP is implemented, the only condition to achieve a transplant is that the patient waiting for an organ presents a potential donor. This means, that logistic aspects are not considered such as the probability or time for performing the pairing, scenarios in which a partner decides to leave the program, or clinical characteristics such as compatibility, age, organ status, etc.; aspects that could influence the effectiveness of this program, and still are an open field for future research.

\section{Fourth Scenario: Both Projects}

By applying the two projects simultaneously into the system, an improvement in the trend of the waiting list size is perceived, similar to the results obtained by implementing the KEP alone. The difference is that a reduction achieved in the waiting list size is faster. 
Under this scenario, for the first years of the simulation, the number of transplanted patients will increase significantly due to the increase that the number of potential donors in the system will have. The number of transplanted patients per year is expected to reach a maximum value by 2017 . From this point on, the number of people who are on the waiting list will gradually decrease and therefore transplants carried out in the following years will be much lower than in 2017.

By 2018, the donation and transplant system will stabilize. However, this does not imply that new patients diagnosed with CKD are avoided. On the contrary, this indicator will gradually increase; since without effective treatment, they will enter the waiting list eventually (see Figure 12).

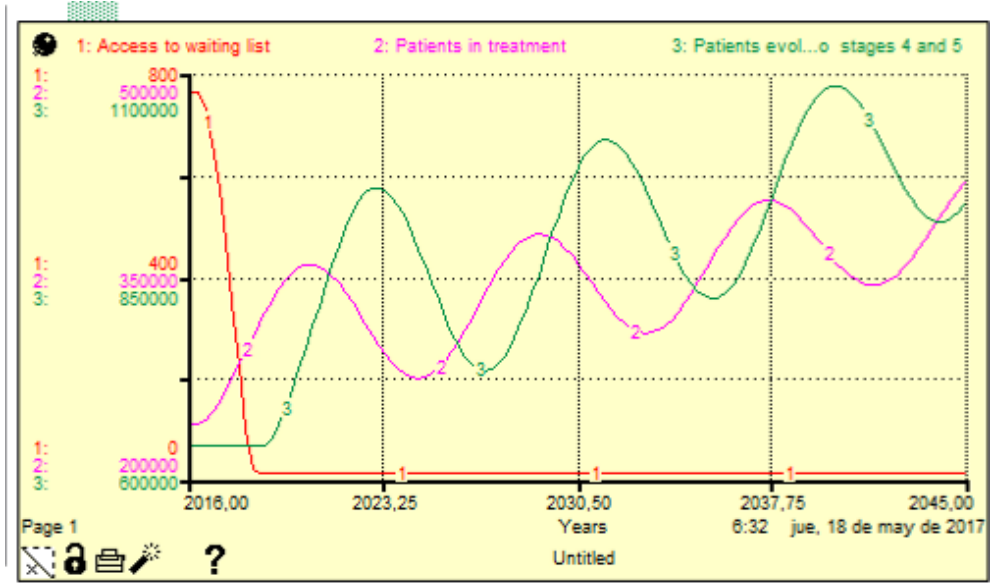

Figure 12. Simulation of patients admitted to waiting list, patient in treatment and patient progress to stage 4 or 5 , under fourth scenario

Source: own work

Finally, there are findings regarding the overall systemic analysis performed. The waiting list increases because patients are often detected in stage 4 and 5 or due to those patients suffering from transplant rejection in their first attempt. The first can be counteracted with a strategy focused on making early detection of $\mathrm{CKD}$, which mainly helps to prevent the list from continuing to grow.

One of the leading causes of uncontrolled increase in the waiting list is the number of patients who reach stage 4 or 5 of CKD. At first, it was attributed to the lack of early detection of the disease. Further analysis, and based on 
the historical records, it can be concluded that even if there is a diagnosis of CKD in early stages (1,2 or 3), currently about $50 \%$ of the diagnosed population does not commit to a renal protection program (3), resulting in an increase of the population susceptible to join the waiting list. Therefore, a path is open for research to establish measures and effective mechanisms to integrate most of the population diagnosed in preventive medical treatments to avoid disease progression.

An alternative to motivate an increase in the number of transplants is to develop awareness campaigns including, for example, the adoption of the amendment to Law 73 of 1988 . The second is the implementation of a KEP, which requires making a broader study that includes legal, logistical, and social aspects of the program implementation.

\section{Discussion and Conclusions}

The study of the system behavior considering kidney procurement and donation in Colombia, particularly the problematic situation concerning the waiting list, provides a global view of the entire system. The organ procurement system in Colombia is a complex social system, as it involves a high volume of variables that require the study of interactions between them and the environment in which they are immersed. Therefore, the use of a tool such as SD is essential for this context, and this study contributes to its fields of application.

The results of this study using SD present a contribution to the healthcare system in particular to the development of strategies for intervention and the kidney donation and procurement system design. The proposed model is based on experts' interviews and a literature review considering scientific articles and current laws in Colombia.

Although it is not SD's intention to predict the future but to understand the complex dynamics within the system, according to this study, if Colombia decides to adopt the KEP in the near future, the system would achieve in time a favorable behavior by reducing the waiting list to reach a point of equilibrium between supply and demand. This represents a significant improvement over the current situation, as the program allows the number of transplant patients to increase in higher proportion than the annual income of people into the waiting list. 
This study explores the modeling of the kidney procurement system in the Colombian context, using an SD approach. The current kidney procurement system is described and compared against the other three different scenarios. These are the implementation of an amendment to Law 73 of 1988, which allows the system to assume organ donation will of every citizen unless an a priori written consent to forbid it is made. Special focus is given to this case. Further, the implementation of a voluntary exchange program is also analyzed, with the aim to develop a national pooling system of CKD patients, each of them having a relative willing to donate a kidney to make voluntary exchanges of kidneys. Finally, the implementation of the amendment to Law 73 along with the implementation of the KEP.

Results allow us to conclude the following findings: with the implementation of the amendment to Law 73 of 1988, the cadaveric donor campaigns loop becomes dominant in the system so that by the year 2023 of the simulation, balance in the waiting list size is achieved. Furthermore, in average, the waiting list for a kidney transplant size is decreased by about 35 patients which is a steady reduction of $98 \%$ by the seventh year of the simulation, under stable endogenous factors.

On the other hand, with the implementation of the KEP as performed in other countries, it is found that the associated reinforcement loop dominates within the system, increasing the number of kidney transplants so that by year 2019 , the average waiting list size is about 23 patients. A steady reduction in the waiting list of $98 \%$ is achieved by the third year of the simulation.

Finally, if the two projects are implemented, the system could find a balance by the third year of the simulation with a sustained reduction in the waiting list of about $99 \%$.

If only a single strategy can be adopted, the implementation of a KEP is recommended since it achieves stability of the system three years earlier than the amendment to Law 73 of 1988, and the reduction in the waiting list size is higher by $37.14 \%$.

Although the most significant variables have been considered, research is still required on this system to examine the impact of other variables such as strategies for reducing and treat high blood pressure and diabetes which have an impact on CKD incidence and prevalence. For future research, it 
is also possible to include economic factors within the analysis such as the cost of treatments, to have a more extensive look into the impacts of the strategies (17). Also, to explore the problem of designing a model that optimizes the KEP, in such a way that medical resources will be used efficiently to perform surgeries, combined with the use of technological tools for gathering information and generating new software to support the model and other findings. Further, making a more in-depth analysis of the causes for Colombian families to refuse their deceased relatives to participate in kidney donation programs is yet an interesting future research topic.

Scenarios of the impact of KEP implementation on the number of CKD deaths on waiting lists.

\section{References}

1. Torres Zamudio C. Insuficiencia renal crónica. Revista Médica Herediana [Internet]. 2003; 14(1):1-4. Available from: http:/www.upch.edu.pe/vrinve/dugic/ revistas/index.php/RMH/article/view/764/730

2. Instituto Nacional de Salud. Informe ejecutivo red de donación y trasplantes [Internet].Bogotá, D.C.; 2015. Available from: https://www.ins.gov.co/Direcciones/ RedesSaludPublica/DonacionOrganosYTejidos/Estadisticas/Informe\%20 Ejecutivo\%20Donaci\%C3\%B3n\%20y\%20Trasplantes\%202016.pdf

3. Acuña-Merchán L, Sánchez-Quintero P, Soler LA. Situación de la enfermedad renal crónica [Internet]. Fondo Colombiano de Enfermedades de Alto Costo, Bogotá, D.C., 2014. Available from: https://cuentadealtocosto.org/site/images/ Publicaciones/Situacion\%20de\%20la\%20ERC\%20Colombia\%202014.pdf

4. Huang S-K, Lin MT, Chen HC, Huang SC, Wu SH. Epidemiology of Kawasaki disease: Prevalence from national database and future trends projection by system dynamics modeling. J Pediatr. 2013; 163(1):126-131. Available from: https://doi. org/10.1016/j.jpeds.2012.12.011

5. Shin N, Kwag T, Park S, Kim SY. Effects of operational \} on the diffusion of epidemic disease: A system dynamics modeling of the merscov outbreak in South Korea. J Theor Biol. 2017; 421 (Supplement C), 39-50. Available from https:// doi.org/10.1016/j.jtbi.2017.03.020

6. Kwak JY, Kwon OJ, Lee KS, Kang CM, Park HY, Kim JH. Exchange-donor program in renal transplantation: a single-center experience. Transplant Proc. 1999; 31(1):344-345. Available from: https:/www.ncbi.nlm.nih.gov/pubmed/10083136

7. Thiel G, Vogelbach P, Gurke L, Gasser T, Lehmann K, Voegele T, Kiss A, Kirste G. Crossover renal transplantation: hurdles to be cleared! Transplant Proc. 2001; 33(1):811-816. Available from: https://www.ncbi.nlm.nih.gov/pubmed/11267078 
8. Abraham DJ, Blum A, Sandholm T. Clearing algorithms for barter exchange markets: Enabling nationwide kidney exchanges. In Proceedings of the 8th ACM conference on Electronic commerce. 2007 Jun 11-15; San Diego, California. 2007 p. 295-304. Available from: https://www.cs.cmu.edu/ sandholm/kidneyExchange. EC07.withGrantInfo.pdf

9. Saidman SL, Roth AE, Sonmez T, Utku M, Ünver, Delmonico FL. Increasing the opportunity of live kidney donation by matching for two-and three-way exchanges. Transplantation. 2006; 81(5):773-782. Available from: https://doi.org/10.1097/01. tp.0000195775.77081.25

10. Veale J, Hil G. National kidney registry: 213 transplants in three years. Clin Transpl. 2010; 333-344.

11. Gurkan A, Kacar SH, Varilsuha C, Tilif S, Coker I, Karaca C, Karaoglan M. Exchange kidney transplantation: a good solution in living kidney transplantation. Transplant Proc. 2004. 36(10): 2952-2953. Available from http://hdl.handle. net/10822/986410

12. Lucan M. Five years of single-center experience with paired kidney exchange transplantation. Transplant Proc. 2007 39(5):1371-1375. Available from: https:// doi.org/10.1016/j.transproceed.2007.02.081

13. Klerk MD, Keizer KM, Claas FHJ, Witvliet M, Haase-Kromwijk BJJM, Weimar W. The Dutch national living donor kidney exchange program. American Journal of Transplantation. 2005; 5(9):2302-2305. Available from: https://doi.org/10.1111/ j.1600-6143.2005.01024.x

14. Klerk M, Witvliet MD, Haase-Kromwijk BJJM, Claas FHJ, Weimar W. A highly efficient living donor kidney exchange program for both blood type and crossmatch incompatible donor-recipient combinations. Transplantation. 2006; 82(12):16161620. Available from: https://doi.org/10.1097/01.tp.0000250906.66728.8d

15. Kranenburg L, Zuidema W, Weimar W, Hilhorst M, Ijzermans J, Passchier J, Busschbach J. Strategies to advance living kidney donation: a single center's experience. Progress in Transplantation. 2009;19(1):71-75. Available from: https:// doi.org/10.1177/152692480901900110

16. Biro P, Manlove DF, Rizzi R. Maximum weight cycle packing in directed graphs, with application to kidney exchange programs. Discrete Mathematics, Algorithms and Applications. 2009;1(04):499-517. Available from: http://eprints. gla.ac.uk/25732/

17. Johnson RJ, Allen JE, Fuggle SV, Bradley JA, Rudge C, et al. Early experience of paired living kidney donation in the United Kingdom. Transplantation. 2008;86(12):16721677. Available from: https://doi.org/10.1097/TP.0b013e3181901a3d.

18. Manlove DF, Omalley G. Paired and altruistic kidney donation in the UK: Algorithms and experimentation. J of Experimental Algorithmics. 2015; 19:2-6. Available from 10.1145/2670129 
19. Ellison B. A systematic review of kidney paired donation: Applying lessons from historic and contemporary case studies to improve the U.S. model. Wharton Research Scholars. 2014. Available from: https://repository.upenn.edu/wharton_research_scholars/107/

20. Fakkert S, Schwarz P, Pruyt E. Kidney transplantations in the United States: A system dynamics approach to reduce the waiting list and illegal tracking. In Proceedings of the 33rd International Conference of the System Dynamics Society. 2015; 1-13.

21. Roth AE. What have we learned from market design? The Economic Journal. 2008; 118(527):285-310. Available from: https://doi.org/10.1111/j.14680297.2007.02121.x

22. Paricio I, Figal J. A system dynamics model of the kidney transplants in the U.S. In Proceedings of the 33rd International Conference of the System Dynamics Society. 2015;1-23. Available from: https://www.systemdynamics.org/assets/ conferences/2015/proceed/papers/P1171.pdf

23. Bruni ME, Conforti D, Sicilia N, Trotta S. A new organ transplantation location-allocation policy: a case study of Italy. Health Care Management Science. 2006; 9(2):125-142.

24. Fajardo-Vallejo E. Emparejamiento voluntario de riñón: Una propuesta para incrementar el número de trasplantes en Colombia. Bachelor thesis, Universidad de los Andes, 2013.

25. Villa S, Patrone F. Incentive compatibility in kidney exchange problems. Health Care Management Science. 2008; 12(4):351-362. Available from: https://doi. org/10.1007/s10729-008-9089-0

26. Ahmadvand S, Pishvaee MS. An efficient method for kidney allocation problem: a credibility-based fuzzy common weights data envelopment analysis approach. Health Care Manag Sci. 2017; 1-17. https://doi.org/10.1007/s10729-017-9414-6

27. Ünver MU. Dynamic kidney exchange. The Review of Economic Studies. 2010; 77(1): 372-414. https://doi.org/10.1111/j.1467-937X.2009.00575.x

28. Zenios SA. Optimal control of a paired-kidney exchange program. Management Science. 2002; 48(3):328-342. Available from: https://www.jstor.org/stable/822569

29. Thompson D, Waisanen L, Wolfe R, Merion RM, McCullough K, Rodgers A. Simulating the allocation of organs for transplantation. Health Care Manag Sci. 2004; 7(4):331-338. Available from: https://doi.org/10.1016/j. socscimed.2017.09.005

30. Sterman JD. Business dynamics: systems thinking and modeling for a complex world. Number HD30. 2 S7835 2000. McGraw-Hill, 2000. 
31. Chang AY, Ogbuoji O, Atun R, and Verguet S. Dynamic modeling approaches to characterize the functioning of health systems: A systematic review of the literature. Soc Sci Med.. 2017; 194(1) 160-167. https://doi.org/10.1016/j. socscimed.2017.09.005

32. Acuña-Merchán L, Sánchez-Quintero P, Soler LA, Piñeros L. Situación de la enfermedad renal crónica, hipertensión arterial y diabetes mellitus en Colombia. Technical report, Fondo Colombiano de Enfermedades de Alto Costo, Bogotá, D.C., 2015. Available from: https:/cuentadealtocosto.org/site/images/ Publicaciones/Situacion_ERC_HA_DM_Colombia_2016.pdf

33. Ojo AO, Hanson JA, Meier-Kriesche H-U, Okechukwu CN, Wolfe RA, Leichtman $\mathrm{AB}$, et al. Survival in recipients of marginal cadaveric donor kidneys compared with other recipients and wait-listed transplant candidates. J Am Soc Nephrol. 2001; 12(3):589-597. Available from: https://www.ncbi.nlm.nih.gov/pubmed/11181808

34. Acosta Roldán Y, Arias-Murillo YR, García S, Salinas Nova MA, Torres Aunta, E et al. Informe Anual Red De Donación Y Trasplantes Colombia Año 2015. Technical Report. Instituto Nacional De Salud Coordinación Nacional Red Donación Y Trasplantes. Bogotá, D.C., Colombia, 2015. Online edition: ISSN 2256-408X. Available from: https:/www.ins.gov.co/Direcciones/ RedesSaludPublica/DonacionOrganosYTejidos/Estadisticas/Informe\%20Red\%20 de\%20Donaci\%C3\%B3n\%20y\%20Trasplante\%202015.pdf

35. Coresh J, Selvin E, Stevens LA, Manzi J, Kusek JW, Eggers P, et al. Prevalence of chronic kidney disease in the United States. Jama. 2007; 298(17):2038-2047.

\section{Appendix A.}

The appendix may be downloaded at http://hdl.handle.net/10818/35221 or by request to william.guerrero1@unisabana.edu.co

\section{This Appendix contains:}

- Scenario 1. Smooth impact of KEP on number of deaths of patients registered on waiting list. Source: Own elaboration.

- Scenario 2. Step wise impact of KEP on number of deaths of patients registered on waiting list. Source: Own elaboration.

- Scenario 3. Exponential decay on the impact of KEP on number of deaths of patients registered on waiting list. Source: Own elaboration.

\section{Appendix B.}

The appendix may be downloaded at http://hdl.handle.net/10818/35221 or by request to william.guerrero1@unisabana.edu.co

This Appendix contains: List of input data for the simulation and sources. 